\title{
Scientific Practice and the Epistemology of Governing Laws
}

ABSTRACT: This article is concerned with the relationship between scientific practice and the metaphysics of laws of nature and natural properties. I begin by examining an argument by Michael Townsen Hicks and Jonathan Schaffer ('Derivative Properties in Fundamental Laws,' British Journal for the Philosophy of Science 20I7) that an important feature of scientific practice-namely, that scientists sometimes invoke non-fundamental properties in fundamental laws-is incompatible with metaphysical theories according to which laws govern. I respond to their argument by developing an epistemology for governing laws that is grounded in scientific practice. This epistemology is of general interest for non-Humean theories of laws, for it helps to explain our epistemic access to nonHumean theoretical entities such as governing laws or fundamental powers.

KEYWORDS: natural properties, governing laws, Humeanism, scientific practice

\section{Introduction}

David Armstrong (1983) and David Lewis (1983) endorse a distinction between natural and non-natural properties, but they accept very different theories of laws. Armstrong holds that laws govern, whereas Lewis holds that laws merely describe. Despite this difference, they agree that fundamental laws of nature involve only perfectly natural properties, so that the metaphysics of laws and the metaphysics of properties are a 'package deal' in which the fundamental laws and the natural properties are discovered together (Lewis I983: 368). In other words, Armstrong and Lewis accept the following principle, which Michael Townsen Hicks and Jonathan Schaffer state as

Link: Only metaphysically elite properties can be invoked in scientifically elite laws. (Hicks and Schaffer 20I7: 4I2)

The importance of this principle cannot be understated, for it forges a tight connection between our best scientific theories and the metaphysics of laws and properties. The idea, in short, is that Link allows us to read off metaphysical accounts of laws and properties from our best science (à la Quine I948; see also Maudlin 2007 and North 2013 for defenses of this sort of method). Jill North summarizes the approach as follows: 'We posit, at the fundamental level, whatever 
the dynamical laws presuppose-whatever there must be in the world for these laws to be true of it' (2013: I 86). Thus, with Link one can show how scientific practice is relevant to the epistemology of metaphysics; this brings the metaphysics of laws and properties down to earth by grounding them in respectable science.

My main goal in this article is to articulate an alternative epistemology of governing laws and natural properties. I focus specifically on Armstrong's type of theory, but the lessons should be applicable to other non-Humean theories as well. Though Armstrong and Lewis both accept Link, we should not expect them to agree on all points concerning the epistemology of laws. Their theories of laws differ significantly. The first step of my project is to explain Hicks and Schaffer's (2017) objections to both Link and governing laws, so in the remainder of this section I clarify the principle Link and the theories of laws in question.

I begin with the term 'metaphysically elite properties'. As Hicks and Schaffer use it, a metaphysically elite property is simply a perfectly natural property. Here is an explanation of perfectly natural properties using Lewis's (I983; I986) terminology (although Armstrong's I989 account is essentially the same). Properties are classes. Since classes are abundant, so are properties. But some properties seem more natural than others, and these privileged properties are sparse. We classify objects to mark respects of similarity, and the natural classes seem to involve genuine similarity among their members, whereas the non-natural classes do not. For example, properties like mass and charge seem more natural than properties like Nelson Goodman's grue (1955). Perfectly natural properties involve exact similarity, and it is perfectly natural properties that are instantiated at the fundamental level. The degree of naturalness of a non-fundamental (derived) property depends at least in part on the complexity of deriving it from the perfectly natural properties. (Perfect naturalness could be primitive, analyzed in terms of universals, and so on, but such disputes are not pertinent to this discussion.)

Below, I argue that the term 'scientifically elite laws' has two distinct interpretations, but the basic idea is simply this: scientifically elite laws are the laws that feature in our most fundamental scientific theories. Consider, for example, this statement from Hicks and Schaffer describing scientifically elite laws as

the ultimate equations that govern the workings of nature, such as (one might once have thought) Newton's $F=m a$ or (one might now think) Schrödinger's equation. (Hicks and Schaffer 20I7: 4I2)

Scientifically elite laws are to be understood in terms of statements of laws, rather than laws themselves, so as to be compatible with both descriptive theories of laws (like Lewis's) and governing theories of laws (like Armstrong's). These two approaches agree on the content of law statements (for example, that it is a law that $F=m a$ ), but they disagree about the underlying nature of the laws themselves (for example, whether laws describe or govern). The scientifically elite statements of laws are supposed to map to the fundamental laws themselves; in other words, statements of laws map directly to whatever it is in nature that answers to the concept of a law, whether the laws themselves are descriptive or governing in 
character. Without such mapping, Hicks and Schaffer worry, our epistemic access to the laws themselves would be somewhat mysterious (20I7: 446). (I return to questions of mapping below, in sections 3 and 4.)

I now explain the distinction between descriptive and governing theories of laws in a bit more detail. As noted above, I take Lewis (I983) and Armstrong (I983) as exemplars. Lewis (1983) endorses a brand of Humean reductionism about laws of nature. It is Humean because it rejects any sort of primitive natural necessity. This rules out primitive governing laws, modally charged relations between universals, fundamental powers, and so on. It is reductionist because it treats laws as mere regularities in the Humean base. Lewis's preferred method of reduction proceeds on the basis of systematic considerations. In simplified form, laws are the regularities that best balance theoretical virtues like simplicity and strength (Lewis I973; Beebee 2000). In addition, Lewis (I983) endorses the constraint that properties featuring in laws must be perfectly natural. However, it is important to note that there are Lewis-inspired Humean best-systems accounts that attempt to do without this constraint. Notably, some such accounts invoke pragmatic criteria for the choice of a best system (Hicks 20I8; Dorst 20I8; Jaag and Loew 20I8). Readers unhappy with the introduction of pragmatic criteria into Humean reductionist theories of laws are encouraged to consult Ned Hall (20 I 2: section 5.6).

In contrast to Lewis, Armstrong endorses a version of the following theory:

Governance: There are entities, governing laws, that do not reduce to other features of nature, but are nonetheless responsible for (i.e., produce, necessitate, etc.) the regularities exhibited in nature.

Armstrong's specific version of Governance holds that governing laws are higher-order states of affairs consisting of irreducible second-order external relations between universals (Dretske I977; Tooley I977; Armstrong 1983). Whenever a nomic relation holds between universals, there is a corresponding regularity among instances of those universals. For example, the relation of nomic necessitation $\mathrm{N}$ is the relation such that, necessarily, for any universals $\mathrm{F}$ and $\mathrm{G}$, if $\mathrm{N}(\mathrm{F}, \mathrm{G})$ holds then so does the regularity that all Fs are Gs. Governing laws such as this operate on perfectly natural properties to 'govern their distribution through space-time' (Hicks and Schaffer 20I7: 444). There is much more that could be said about Armstrong's theory of laws, but for my purposes this discussion suffices to show that statements of fundamental laws must describe regularities among instances of universals (and thus among perfectly natural properties). This is essential to Armstrong's version of Governance. Although Lewis incorporates a naturalness constraint into his theory of laws, this constraint does not seem essential to Humean reductionism-at least not for analogous reasons. This is important, because it suggests that a failure of the principle Link would be more problematic for Armstrong's theory of laws than it would be for Lewis's.

For convenience, henceforth I use Governance to refer only to those governing theories that, like Armstrong's, allow only perfectly natural properties to feature in fundamental laws. However, I view it as an open question whether Hicks and Schaffer's objection actually applies to all versions of Governance. For example, I 
am not sure that it applies to theories that analyze governing laws in terms of a powerful God (Foster 2004; Swinburne 2006), since there is no obvious reason why God could not decree that there be regularities among non-fundamental properties. For similar reasons, it may not apply to the primitivist theories of John Carroll (I994) and Tim Maudlin (2007), since it seems compatible with their views that laws could be fundamental without operating on the fundamental level.

With this background in place, Hicks and Schaffer's objection to Governance can be stated easily. It has two main premises. First, Link is false (because scientifically elite laws can involve derivative, non-fundamental properties). Second, Governance requires Link (whereas Humean reductionism does not). I proceed as follows. In section I, I explain Hicks and Schaffer's objection to Link. In section 2, I explain their argument that Governance requires Link. In section 3, I distinguish between two interpretations of Link and show how this distinction can be employed to save Governance from Hicks and Schaffer's objection. However, I explain why an epistemological challenge for Governance remains. And in section 4, I meet that challenge by providing an account of the epistemology of governing laws that is based on scientific practice. This is significant, for it is not uncommon for Humeans to motivate their views in part by citing their fit with scientific practice (Hicks and Schaffer 20I7; Earman and Roberts 2005a and 2005b; Loewer 2007; Cohen and Callender 2009). In addition to providing a response to Hicks and Schaffer's objection, my account provides general guidance for how we should think about the epistemology of non-Humean theoretical entities.

\section{Hicks and Schaffer's Argument for Derivative Properties in Fundamental Laws}

Hicks and Schaffer's objection to Link is based on considerations of scientific practice. In a nutshell, the idea is that paradigm laws-such as Newton's second law of motion or Schrödinger's equation-involve properties that are less than perfectly natural. For example, in Newtonian mechanics, acceleration (the $a$ in $F=$ $m a)$ is irreversibly defined as the second derivative of position' (Hicks and Schaffer 20I7: 4I2). Namely, $a=d v / d t=d^{2} x / d t^{2}$. (Force $F$ is derived as well, but that can be ignored here for the sake of brevity.) Because universals are fundamental and $a=d^{2} x / d t^{2}$, Armstrong cannot treat both position and acceleration as universals. Indeed, there is good reason to think that position is the more fundamental property: the definition is irreversible. Facts about acceleration are uniquely determined by facts about position, but facts about acceleration do not uniquely determine facts about position. Acceleration, then, is derived from position; it is not metaphysically elite. Thus, if $F=m a$ is in fact a scientifically elite law, it is an example of a scientifically elite law that involves a derivative, non-fundamental property.

This conclusion might sound too hasty. One worry is that Newton's laws of motion are no longer regarded as paradigm statements of laws, and thus we ought not to regard $F=m a$ as scientifically elite. I set this worry aside, because Hicks and Schaffer argue (convincingly, I think) that the relevant features of Newton's second law are exhibited in other paradigm statements of laws as well. Another 
worry is based on the obvious fact that the following two equations are mathematically equivalent:
(I) $F=m a$
(2) $F=m \frac{d^{2} x}{d t^{2}}$

Why not take equation (2) to be scientifically elite instead of equation (I)? After all, it does not include the derivative property of acceleration. However, those who accept Link are committed to a view that Hicks and Schaffer call term objectivism, according to which 'there is a fact of the matter as to the right terms to use, even when the choices are mathematically equivalent' (Hicks and Schaffer 20I7: 4I7I9). Equations (I) and (2) are mathematically equivalent statements of laws. But for Armstrong, only one statement can properly map to the law itself. The nomic relation must relate one universal-position or acceleration-rather than the other. As the syntax of equations (I) and (2) suggests, a governing law involving acceleration would be structurally different than a scientifically equivalent governing law involving position. Term objectivism, then, is not an odd position when viewed through the lens of a metaphysically robust theory of laws such as Armstrong's. Thus, although equations (I) and (2) are indeed mathematically equivalent, that does not imply that they are equally well suited to describing the fundamental metaphysical structure of laws themselves.

Thus, at most one of these equations can count as a scientifically elite law. Which is it? Hicks and Schaffer argue that it is equation (I) rather than (2). More precisely, they argue that at least we should be willing to treat $F=m a$ as scientifically elite; it is not up to philosophers, but rather to scientists, to determine what is scientifically elite (Hicks and Schaffer 20I 7: 42I). In other words, scientists are the arbiters of scientific eliteness. They tell us which statements are statements of scientifically elite laws. Once we take this step, there is good reason to think that $F=m a$ (or a statement of law like it in relevant respects) could be a paradigm example of a scientifically elite law. After all, ask a bunch of physicists for a paradigm example of a law of nature, and many will offer $F=m a$.

This answer is not arbitrary. There are at least two good reasons why physicists might consider equation (I), but not equation (2), to be scientifically elite. The first is simplicity; it is just simpler, easier, to write $F=m a$ (Hicks and Schaffer 2017:428). The second is transparency: the statement $F=m a$ makes it very clear that acceleration is dynamically relevant and invariant under various symmetry transformations (Hicks and Schaffer 20I7: 428). Hicks and Schaffer acknowledge that these criteria are pragmatic:

All physicists realize that acceleration is a defined notion in Newtonian mechanics, but happily allow this notion in formulating the elite equations of Newtonian mechanics nonetheless, because it is useful. (2017:428)

We also emphasize that simplicity and transparency are in a sense pragmatic. Our point is that the conditions for being a scientifically 
elite equation are partly pragmatic. (This is in contrast to the conditions for being a metaphysically elite property, which are usually taken to be fully realistic and objective matters.) We think that the real lesson of Newtonian acceleration is that, in contrast to the idea in Link that physicists always insist on metaphysically elite terms, physicists are in practice happy to trade some metaphysical non-eliteness for sufficient practical gains in matters such as mathematical simplicity and dynamical transparency. To the extent that we can expect the physicists to deliver certain basic equations at all, we can expect that their choice of equations will be partly guided by pragmatic constraints. That is why metaphysically non-elite properties can be invoked in scientifically elite equations ... And that is also why Link is broken: it tries to forge a tight connection between the real and objective structure of nature (metaphysically elite properties) and what turns out to be a partly pragmatic matter of convenience (term choice in the scientifically elite equations). (Hicks and Schaffer 2017: 428, emphasis added)

Hicks and Schaffer claim that pragmatic considerations are at the heart of what it is for a law to be scientifically elite. With considerations like these at our disposal, we can indeed make a strong case for treating equation (I) rather than equation (2) as scientifically elite.

I conclude this section with some comments on the operative conception of scientific eliteness in Hicks and Schaffer's argument against Link. As the above two quotations from Hicks and Schaffer make clear, the property of scientific eliteness is partly pragmatic. Whether a statement of law has the property is a matter to be settled by scientists rather than by metaphysicians. This suggests something like the following:

Scientifically elite laws, practice-based $\left(\mathrm{SEL}_{\mathrm{P}}\right)$ : Scientifically elite laws are whatever human scientists (not metaphysicians) say they are.

Here, scientific eliteness is a property grounded in the actual practice of science. It allows pragmatic influences because it is tied to human science.

At this point, I think it is important to revisit the initial definition of scientifically elite laws (henceforth, SEL) provided by Hicks and Schaffer:

the ultimate equations that govern the workings of nature, such as (one might once have thought) Newton's $F=m a$ or (one might now think) Schrödinger's equation. (20I7: 4I2)

There is more to this conception of scientific eliteness than is identified in SEL . Indeed, SEL seems to be a conjunctive notion that includes both pragmatic scientific eliteness $\left(\mathrm{SEL}_{P}\right)$ together with a metaphysically loaded brand of scientific eliteness. (In section 3, I discuss Hicks and Schaffer's epistemological argument for joining these two elements.) This is because SEL contains metaphysically 
loaded vocabulary that $\mathrm{SEL}_{P}$ does not-namely, 'ultimate' and 'govern' - that seems to point toward a more realistic and objective conception of fundamental laws.

I have more to say about this in the sections that follow. For now, what matters is simply that Hicks and Schaffer's objection to Link is based only on the pragmatic part of scientific eliteness - namely, the part articulated by SEL $L_{P}$. Below, I consider whether their argument that Governance requires Link involves the metaphysically loaded part of scientific eliteness. I also consider whether the pragmatic and metaphysical components are separable or tightly joined.

\section{Why Governance Requires Link}

Hicks and Schaffer argue that Governance requires Link. Here is what they say:

Fundamental Governing: Scientifically elite laws operate only on metaphysically elite properties to govern their distribution through space-time. (Hicks and Schaffer 2017: 444)

This picture [i.e., Fundamental Governing] views scientifically elite nomic connections as extra threads woven through the fundamental fabric of reality, holding it all together and governing how the fabric rolls out through time, thereby allowing for a distinctive sort of explanatory connection between events that no mere deflationary conception of lawhood can match. (Hicks and Schaffer 20I7: 445)

Fundamental Governing requires Link. For if the scientifically elite laws are operating at the fundamental level to govern the distribution of metaphysically elite properties, then of course they can only relate the metaphysically elite properties. (Hicks and Schaffer 20I7: 445)

I believe that Fundamental Governing is intended to be equivalent to Governance. Hicks and Schaffer's use of 'scientifically elite' in the initial definition might be thought to shed some doubt on this claim, but I think the second paragraph quoted above provides strong evidence that Fundamental Governing equals Governance. In addition, they cite both Armstrong (I983) and Maudlin (2007) as proponents.

The claim that Governance requires Link seems eminently plausible when viewed from Armstrong's perspective. For Armstrong, fundamental laws (the entities that map to the scientifically elite laws) are relations between universals; accordingly, the regularities they directly explain must involve those very same universals. Insofar as science is directed toward the discovery of Armstrongian laws, it must be directed toward laws that involve only perfectly natural properties.

What conception of scientific eliteness is required for the argument above? Consider the occurrence of 'scientifically elite laws' in Hicks and Schaffer's definition of 'Fundamental Governing'. In their argument that Governance requires Link, Hicks and Schaffer explicitly say that the scientifically elite laws 'operate' and 'govern'. Moreover, their argument does not invoke pragmatic 
considerations. Their argument requires scientifically elite laws to be interpreted realistically, in a way that seems wholly independent of pragmatic concerns like simplicity and transparency. Thus, $\mathrm{SEL}_{P}$ does not capture the operative conception of scientific eliteness in the argument that Governance requires Link. Instead, it seems that the operative concept of a scientifically elite law is intimately connected to the concept of a governing law, in something like the following way:

Scientifically elite laws, governing $\left(\mathrm{SEL}_{\mathrm{G}}\right)$ : statements of laws that correspond exactly to the governing laws (i.e., the entities that play the governing role, such as Armstrong's relations between universals).

It is not surprising that the argument would invoke something like this conception. Although the argument against Link is based on pragmatic features of scientific practice, the argument that Governance requires Link is based purely on the metaphysics of governing laws. Thus, this argument appeals to only the governing component of SEL, not to the pragmatic component.

\section{Response to Hicks and Schaffer's Argument, and the Epistemological Premise}

In sections I and 2, I argued that the two main premises of Hicks and Schaffer's argument invoke different conceptions of scientific eliteness. In everyday terms, $\mathrm{SEL}_{P}$ expresses the concept of a law that is fundamental in the sense that it is a statement of law preferred by natural scientists, whereas SEL $\mathrm{S}_{G}$ expresses the concept of a governing law that is fundamental in an objective, observer-independent sense. Since Link includes the term 'scientifically elite laws', we have two versions of Link as well:

$\operatorname{Link}_{\mathrm{P}}$ : Scientifically elite laws (in the sense of $\mathrm{SEL}_{P}$ ) must involve only perfectly natural properties.

$\operatorname{Link}_{\mathrm{G}}$ : Scientifically elite laws (in the sense of $\mathrm{SEL}_{G}$ )-i.e., governing lawsmust involve only perfectly natural properties.

Hicks and Schaffer's first premise is an objection to $\operatorname{Link}_{P}$; their second premise shows that Governance requires $\operatorname{Link}_{G} \cdot{ }^{\text {I }}$ Given the arguments thus far, proponents of Governance can say that $F=m a$ is scientifically elite in the sense of $\operatorname{SEL}_{P}$, and that $\operatorname{Link}_{P}$ is false. And they can say that $F=m\left(d^{2} x / d t^{2}\right)$ is scientifically elite in the sense of $\mathrm{SEL}_{G}$, and maintain that $\mathrm{Link}_{G}$ is true. If the two conceptions of scientific eliteness do turn out to be separable in this way, Hicks and Schaffer's objection to Governance does not succeed.

The question, then, is whether there is a connection between the two conceptions of scientifically elite laws. Above, I note that Hicks and Schaffer appeal to a

\footnotetext{
${ }^{\text {I }}$ Hicks and Schaffer's official summaries of the arguments in support of their two main premises appear on pages 420 and 445 of their article. My claim in this section is that their premises (I) through (3) require Link , $_{P}$ whereas (4) through (6) require Link $_{G}$.
} 
conjunctive definition of scientific eliteness that involves both pragmatic and metaphysical elements. Why do they do this?

Hicks and Schaffer argue on epistemological grounds that Governance requires a conception of scientific eliteness that is grounded in scientific practice. In their introduction, they warn against a certain kind of maneuver:

As will emerge, there are ways to 'defend' Link that rob it of much of its substance, either by refusing to give independent content to 'metaphysically elite properties', or by refusing to give independent content to 'scientifically elite laws' beyond those in which the metaphysically elite properties are invoked (in which case the idea of a scientifically guided metaphysics is lost). (Hicks and Schaffer 20I7: 4I4)

As I said above, the primary motivation behind Link is to make the metaphysics of laws and properties epistemically accessible by grounding them in the practice of science. I agree that the metaphysics of laws and properties should be so grounded. The question, then, is whether $\operatorname{Link}_{G}$ commits one of two sins.

The first sin is to define metaphysical eliteness in terms of scientific practice. This sin has not been committed, since the notion of a metaphysically elite property is captured by the account of natural properties discussed in my introduction to this article.

The second sin is to define scientific eliteness in terms of metaphysically elite properties. This sin looks unforgivable because it severs the tie between science and metaphysics, threatening the epistemology of both laws and properties. Thus Hicks and Schaffer:

But if the proponent of Fundamental Governing denies that laws and laws-statement (whether scientifically elite or not) have a direct correspondence, then we lose our grip on what she even has in mind by 'laws'. All she will find in the science textbooks are law-statements. And all she will find in scientific practice are law-statements in use. Scientific explanation involves law-statements, not laws. Separated and disconnected from the law-statements that do all the work in science, her 'laws' (scientifically elite or not) would become a mere metaphysical invention unworthy of our credence. (Hicks and Schaffer 20I7: 446)

This is a reasonable concern, for nothing in $\mathrm{SEL}_{G}$ provides any hints about what an adequate epistemology of governing laws might look like. Indeed, I think it is possible that the statements scientists prefer to count as paradigm laws $\left(\mathrm{SEL}_{P}\right)$ will not be exactly the same as the statements that correctly limn the metaphysical structure of the laws themselves $\left(\mathrm{SEL}_{G}\right)$. My response to Hicks and Schaffer's argument sketched above requires this sort of possibility. And does that not suggest that $\mathrm{SEL}_{G}$ is somehow floating free of scientific practice? If this is right, then we might have no recourse but to treat $\operatorname{Link}_{P}$ as a requirement of Governance after all. That is, we might be forced to tie $\mathrm{SEL}_{G}$ to $\mathrm{SEL}_{P}$ by stipulation, 
identifying the $\mathrm{SEL}_{G}$ statements of laws with the $\mathrm{SEL}_{P}$ statements of laws. This would be to treat scientific eliteness conjunctively, so that it includes both pragmatic and metaphysical elements, just as Hicks and Schaffer suggest. If this is correct, the response I propose to Hicks and Schaffer's objection to Governance would fail. However, as I argue below, an adequate epistemology for Governance can be developed so that it is not necessary for proponents to tie $\mathrm{SEL}_{G}$ to $\mathrm{SEL}_{P}$ in this sort of way.

\section{An Epistemology for Governance}

In this section I offer an epistemology for Governance that is grounded in scientific practice, but does not force proponents of Governance to invoke $\operatorname{Link}_{P}$ as the only means of grounding the epistemology of governing laws in scientific practice. In doing so, I operate under the assumption that we have good reason to think that our best scientific theories are true. If we reject that assumption, humility regarding which laws and properties our world contains is the correct response, regardless of our metaphysics of laws.

I begin by providing an account that explicitly identifies a link between which governing laws there are and scientific practice:

Governance and Scientific Practice (GSP): The governing laws and perfectly natural properties in our world are those that explain why our world contains the regularities described by scientifically elite $\left(\mathrm{SEL}_{P}\right)$ statements of laws.

As noted above, the explanation of regularities here is metaphysical in character. Governing laws explain regularities by producing/necessitating them (or whatever). According to GSP, it is precisely this explanatory power of non-Humean laws that is relevant for which lawlike regularities there are. This has implications for which package of laws and properties we ought to accept. Namely, we should posit a package of laws and properties that can explain why our world contains regularities of the sort uncovered by our best science. Some readers might object to the claim that governing laws explain. I address this objection below. Others might worry that the way in which scientific practice is consulted here-namely, with scientists merely supplying philosophers with lists of regularities-constitutes a concession to Humeans. I do not think this is so. Humeans and proponents of Governing Laws can and do agree about which regularities are lawlike. Indeed, insofar as we learn which regularities are lawlike through science, one would hope that Humeans and non-Humeans agree about this. Their disagreement concerns that which makes the regularity lawlike. For this reason, I do not think GSP's appeal to regularities constitutes a concession to Humeans.

Although GSP involves SEL ${ }_{P}$, it does not require $\operatorname{Link}_{P}$. Why not? Governing laws are posited to explain regularities described by $\mathrm{SEL}_{P}$ statements of laws, but the explanation need not be direct. A regularity described by an $\mathrm{SEL}_{P}$ statement of law need not be explained by positing a governing law involving exactly the same 
properties referenced in the $\mathrm{SEL}_{P}$ statement of law. For example, let's consider again equations (I) $F=m a$ and (2) $F=m\left(d^{2} x / d t^{2}\right)$. Suppose that proponents of Governance decide that $(\mathrm{I})$, though scientifically elite $\left(\mathrm{SEL}_{P}\right)$, is not a statement of a governing law $\left(\mathrm{SEL}_{G}\right)$. Instead, they take (2) to be a statement of a governing law, so they posit a relation between universals capable of explaining (2) directly. This governing law will also explain why the regularity described by (I) obtains, but in two steps rather than one:

Step I: The governing law directly explains the regularity described by (2).

Step 2: The regularity described by (I) follows from the regularity described by (2) given the definition of acceleration.

In this case, scientific practice plays an essential role in settling the question of which laws and properties there are. It helps non-Humean metaphysicians to determine which regularities are in need of explanation, but it allows a degree of freedom concerning just how those regularities are to be explained. That is why $\operatorname{Link}_{P}$ is not required and Link $_{G}$ can be upheld, even though GSP uses SEL $\mathrm{L}_{P}$.

One can generalize. Rather than simply reading off the ontological commitments of our best scientific theories, taking scientists' preferred statements of laws at face value as suggested by Hicks and Schaffer (20I7: 4I4), we can use the following method:

Method: First, ask scientists for the statements of laws. (Everyone must do thisor something like it-if their epistemology of laws is to be grounded in scientific practice.) Second, invoke a package of governing laws and natural properties capable of explaining-directly or indirectly-the regularities described by these statements of laws.

Sometimes the explanation of regularities will be direct. In cases in which scientists' preferred statements of laws involve properties that are non-derived by the lights of their theory, proponents of Governance may (and probably should) posit a governing law that involves exactly the same properties that feature in the scientists' preferred statement of law. However, as illustrated in the example above, the explanation does not have to be direct; the fundamental properties featured in our governing laws need not map directly to the properties featured in convenient or otherwise pragmatically motivated statements of laws-especially when the latter properties are derived by the lights of the theory. Thus, although my method allows one-step direct explanations, explanations of this sort are not required. This is important because it illuminates a structural difference between reading off ontological commitments and explaining regularities. Here, again, is North's statement of method: 'We posit, at the fundamental level, whatever the dynamical laws presuppose-whatever there must be in the world for these laws to be true of it' (North 2013: I 86). We can highlight the contrast between the two epistemological approaches by redescribing GSP and its associated Method in 
parallel terms: We posit, at the fundamental level, whatever laws and properties can explain the regularities described by the scientists' preferred statements of dynamical laws.

This structural difference leads to an additional benefit of GSP and the associated Method. Hicks and Schaffer suggest that term objectivism is problematic in the following way (though they set this concern aside for the sake of argument): When faced with mathematically equivalent formulations of the same law, North's method requires philosophers to ask scientists for the elite version; however, it is unrealistic to expect scientists to deliver that (Hicks and Schaffer 20I7: 4I8). If Hicks and Schaffer are right, it is unclear how the method described by North is supposed to get off the ground. However, by the lights of GSP, just as it does not matter which equation is viewed as 'scientifically elite' by the scientists, it does not matter if there is no equation with such status. Provided that scientists agree on the basic regularities (for example, by invoking various but equivalent equations to describe them), proponents of GSP can employ Method. Metaphysicians do not require information from scientists about which claims exactly constitute scientifically elite laws; information about the scientific theories themselves, including various statements of laws, and information about relationships between properties featuring in such statements will suffice. And if scientists do not agree about the basic regularities (are unsure which theory is true)? In that case, humility about which governing laws and natural properties our world contains seems entirely appropriate.

As I discuss at the end of section 3 , Hicks and Schaffer argue that proponents of Governance should identify $\mathrm{SEL}_{G}$ statements of laws with $\mathrm{SEL}_{P}$ statements of laws (and thus should join $\operatorname{Link}_{G}$ to $\operatorname{Link}_{P}$ ) in order to allow an adequate epistemology for governing laws. I have provided an alternative epistemology: GSP and its associated Method. It allows scientific practice to play a crucial role in the epistemology for governing laws, for it is scientific practice that illuminates which regularities are in need of explanation. (It is worth noting that it does not ask metaphysicians to accept everything the scientists say at face value, and it does not tell scientists how to practice science either.) But it does not require us to identify the $\mathrm{SEL}_{G}$ statements of laws with $\mathrm{SEL}_{P}$ statements of laws. And it does not require $\operatorname{Link}_{P}$ and $\operatorname{Link}_{G}$ to stand or fall together. Indeed, it allows proponents of Governance to accept $\operatorname{Link}_{G}$, thus maintaining the link between fundamental governing laws and perfectly natural properties, while accepting Hicks and Schaffer's argument that $\operatorname{Link}_{P}$ is false. Thus, I believe that Hicks and Schaffer's objection to Governance fails.

Before closing, I consider two potential worries for the epistemology I have developed. First, as I noted earlier, Link ${ }_{G}$ looks suspiciously similar to a principle considered by Hicks and Schaffer:

There is even a use of 'fundamental' that can make Link look almost truistic. Call a metaphysically elite property a 'fundamental property', and a scientifically elite law a 'fundamental law'. Then one can express Link as: 
Link, Rewired: Only fundamental properties can be invoked in fundamental laws. But it must be understood that 'fundamental' is being used equivocally in Link, Rewired, first to mark a metaphysical status, and then to mark a scientific status. (Hicks and Schaffer 20I7: 4I4)

Link $_{G}$ includes SEL ${ }_{G}$ instead of SEL in its initial generic form, so it does not make this equivocation. However, with GSP and Method, I have shown that this does not mean that we are condemned to ignorance of laws and natural properties, because their epistemology is still closely tied to our best science.

Second, my account of the epistemology of governing laws is grounded in the explanatory power of governing laws, but one might object that governing laws cannot explain. One possible response is to argue that they can explain (Foster I982-I983; Fales I990: chapter 4; Maudlin 2007: chapter 6; Bird 2007: 86-90; Hildebrand 2013). Another response is to note that if governing laws cannot explain, there would be little reason to posit them in the first place. The putative advantages of Governance are many, but among the most important are these: governing laws explain, they distinguish lawlike from accidental regularities, they support counterfactuals, and they support induction (Armstrong 1983: 99-107). The first grounds the latter three. If laws cannot explain their past instances, it is unclear what they say about future instances or non-actual instances. And if relations between universals do not explain their instances then it is not clear why they are even relevant to the distinction between lawlike and accidental regularities. If we were justified in thinking that governing laws did not explain, we would not need an argument from scientific practice to challenge Governance. Thus, the crucial question for my purposes is whether proponents of Governance can accommodate scientific practice into their overall metaphysical and epistemological worldview. Since they tend to think that governing laws can explain, the objection under consideration has little dialectical force. Similar remarks apply to concerns related to van Fraassen's inference problem. See van Fraassen (I989: chapter 5) for a formulation, and Schaffer (2016) for a response.

\section{Conclusion}

I believe that Hicks and Shaffer's objection to Link is both correct and important when it is properly interpreted. However, I have argued that their overall objection to Governance rests on a failure to consider an appropriate epistemology, which I provided in section 4. Hicks and Schaffer should not be faulted for this oversight. To my knowledge, no one has previously articulated an epistemology for governing laws that explains how scientific practice might be incorporated when there are various mathematically equivalent statements of laws in play. My account was made possible in large part because of the clarity, precision, and thoroughness of Hicks and Schaffer's arguments. Indeed, the epistemology is strongly informed by the work Hicks and Schaffer do in their objection to Link and subsequent discussion.

The epistemology for Governance I have suggested is important for two additional reasons. First, anyone who posits theoretical entities owes an account 
of our epistemic access to those entities. Proponents of Governance can use the method I have recommended to explain our epistemic access. With minimal adjustments, so too can other sorts of non-Humean. Indeed, anyone who posits non-Humean laws or properties to play an explanatory role can presumably make use of this method. This includes dispositionalists who derive laws from dispositional properties in a direct sort of way (Bird 2007), dispositionalists who derive laws from dispositional properties by way of a best systems account (Demarest 20I7), and natural kind essentialists such as Brian Ellis (200I). (That said, I do not want to claim that it is available to all non-Humeans. I worry, for example, that primitive laws lack the relevant sort of explanatory power over regularities [Hildebrand 20I3].) Second, the method I have recommended clarifies the role of scientific practice in the epistemology of Governance. I view this as a friendly elaboration on the details of Armstrong's view that questions about which laws and properties there are should be decided on the basis of total science. As I noted earlier, many Humeans motivate their views in part by appealing to their nice fit with scientific practice (Earman and Roberts 2005a, 2005 b; Loewer 2007; Cohen and Callender 2009; Hicks and Schaffer 20I7). The epistemology I have provided suggests that non-Humeans too can claim a nice fit with scientific practice. A careful exploration of the degrees and types of fit would thus be required in order to claim that scientific practice favors one sort of theory over another.

I conclude by considering one last question: What do my arguments suggest about the orthodox position expressed naturally by saying that laws and properties are discovered together as a package deal? The package deal approach includes both metaphysical and epistemological elements. Metaphysically, it says that laws involve only perfectly natural properties. Epistemologically, it says that which laws and which properties are instantiated in our world are discovered together. Proponents of Governance can accept both the metaphysical and epistemological theses, provided that they are justified in positing laws to play an explanatory role. Are they so justified? That is an important question-perhaps the most important question in the debate between Humeans and non-Humeans-but not one that I can consider here.

TYLER HILDEBRAND (D)

DALHOUSIE UNIVERSITY

hildebrand@dal.ca

\section{References}

Armstrong, David. (1983) What is a Law of Nature? Cambridge: Cambridge University Press. Armstrong, David. (1989) Universals: An Opinionated Introduction. Boulder, CO: Westview Press. Beebee, Helen. (2000) 'The Non-Governing Conception of Laws of Nature'. Philosophy and Phenomenological Research, 6I, 57 I-94.

Bird, Alexander. (2007) Nature's Metaphysics: Laws and Properties. Oxford: Clarendon Press.

Carroll, John W. (1994) Laws of Nature. Cambridge: Cambridge University Press.

Cohen, Jonathan, and Craig Callender. (2009) 'A Better Best System Account of Lawhood'. Philosophical Studies, I45, I-34. 
Demarest, Heather. (20I7) 'Powerful Properties, Powerless Laws'. In Jonathan Jacobs (ed.), Causal Powers (Oxford: Oxford University Press), $38-53$.

Dorst, Chris. (2018) 'Toward a Best Predictive System Account of Laws of Nature'. British Journal for the Philosophy of Science, axyor6. https://doi.org/I0.1093/bjps/axyor6.

Dretske, Fred. (1977) 'Laws of Nature'. Philosophy of Science, 44, 248-68.

Earman, John, and John T. Roberts. (2005a) 'Contact with the Nomic: A Challenge for Deniers of Humean Supervenience about Laws of Nature Part I: Humean Supervenience'. Philosophy and Phenomenological Research, 7I, I-22.

Earman, John, and John T. Roberts. (2005b) 'Contact with the Nomic: A Challenge for Deniers of Humean Supervenience about Laws of Nature Part II: The Epistemological Argument for Humean Supervenience'. Philosophy and Phenomenological Research, 7I, 253-86.

Ellis, Brian. (200I) Scientific Essentialism. Cambridge: Cambridge University Press.

Fales, Evan. (I990) Causation and Universals. New York: Routledge.

Foster, John. (I982-1983) 'Induction, Explanation, and Natural Necessity'. Proceedings of the Aristotelian Society, 83, 87-IOI.

Foster, John. (2004) The Divine Lawmaker: Lectures on Induction, Laws of Nature, and the Existence of God. Oxford: Clarendon Press.

Goodman, Nelson. (1955) Fact, Fiction, and Forecast. Cambridge, MA: Harvard University Press.

Hall, Ned. (2OI2) 'Humean Reductionism about Laws of Nature'. https://philarchive.org/archive/ HALHRAvi.

Hicks, Michael Townsen. (2018) 'Dynamic Humeanism'. British Journal for the Philosophy of Science, 69, 983-1007.

Hicks, Michael Townsen, and Jonathan Schaffer. (2017) 'Derivative Properties in Fundamental Laws'. British Journal for the Philosophy of Science, 68, 4 I I-50.

Hildebrand, Tyler. (2013) 'Can Primitive Laws Explain?' Philosophers' Imprint, I3 (I 5 ), I-I 5.

Jaag, Siegfried, and Christian Loew. (201 8) 'Making Best Systems Best for Us'. Synthese. https:/link. springer.com/article/IO.I007\% 2Fsi I 229-OI 8-I 829-I.

Lewis, David. (1983) 'New Work for a Theory of Universals'. Australasian Journal of Philosophy, 6I, 343-77.

Lewis, David. (1986) On the Plurality of Worlds. Oxford: Blackwell.

Loewer, Barry. (2007) 'Laws and Natural Properties'. Philosophical Topics, 35, 3I3-28.

Maudlin, Tim. (2007) The Metaphysics within Physics. Oxford: Oxford University Press.

North, Jill. (2013) 'The Structure of a Quantum World'. In Alyssa Ney and David Z. Albert (eds.), The Wave Function: Essays on the Metaphysics of Quantum Mechanics (Oxford: Oxford University Press), I $84-202$.

Quine, Willard V. (1948) 'On What There Is'. Review of Metaphysics, 2, 2 I-38.

Schaffer, Jonathan. (2016) 'It is the Business of Laws to Govern'. Dialectica, 70, 577-88.

Swinburne, Richard. (2006) 'Relations between Universals, or Divine Laws?' Australasian Journal of Philosophy, 84, I79-89.

Tooley, Michael. (1977) 'The Nature of Laws'. Canadian Journal of Philosophy, 7, 667-98. van Fraassen, Bas C. (1989) Laws and Symmetry. Oxford: Clarendon Press. 